\title{
Prolnflammatory Mediators, Stimulators of Sensory Neuron Excitability via the Expression of Acid-Sensing Ion Channels
}

\author{
Julien Mamet, Anne Baron, Michel Lazdunski, and Nicolas Voilley \\ Institut de Pharmacologie Moléculaire et Cellulaire, Centre National de la Recherche Scientifique-Unité Mixte de \\ Recherche 6097, Sophia Antipolis, 06560 Valbonne, France
}

Tissue acidosis is an important feature of inflammation. It is a direct cause of pain and hyperalgesia. Protons activate sensory neurons mainly through acid-sensing ion channels (ASICs) and the subsequent membrane depolarization that leads to action potential generation. We had previously shown that ASIC transcript levels were increased in inflammatory conditions in vivo. We have now found that this increase is caused by the proinflammatory mediators NGF, serotonin, interleukin-1, and bradykinin. A mixture of these mediators increases ASIC-like current amplitude on sensory neurons as well as the number of ASIC-

Inflammation represents a protective defense reaction induced by external or internal trauma such as tissue injury, infection, or tumor growth. However, it represents one of the major causes of pain. The numerous inflammatory and pain mediators that are involved, released by fibroblasts, neurons, and immune cells, include neurotrophins (such as NGF), histamine, bradykinin, prostanoids $\left(\mathrm{PGE}_{2}, \mathrm{LTB}_{4}\right)$, serotonin, protons, cytokines [interleukin (IL)-1, IL-6], peptides (substance P), and free radicals (Dray, 1995). They can have a direct action or stimulate the release of other chemicals, activate the immune system, facilitate vasodilatation and plasma extravasation, and sensitize the nociceptive system. This latter action is accomplished by their binding to receptors on sensory neurons, leading to downstream secondmessenger cascades and modulation of ion channel gating. Some of these mediators can change gene expression, modifying the phenotype of these neurons (Woolf and Costigan, 1999). Inflammation is thus accompanied by short-term modifications in the excitation and sensitization of peripheral sensory terminals (Rang et al., 1991; Cesare and McNaughton, 1997) and longer-term changes in the properties of these afferent neurons innervating the inflamed tissue (Neumann et al., 1996; Woolf, 1996), leading to a decrease in their excitability threshold. Combined with an increase in excitability of spinal neurons (McMahon et al., 1993), this facilitated nociceptive transduction leads to hyperalgesia (i.e., responses to noxious stimuli are enhanced) and allodynia (i.e., innocuous stimuli produce pain).

\footnotetext{
Received Aug. 14, 2002; revised Oct. 2, 2002; accepted Oct. 2, 2002.

This work was supported by the Centre National de la Recherche Scientifique (CNRS), the Association de la Recherche contre le Cancer, the Association Française contre les Myopathies, AstraZenecaAB Research Area CNS/Pain, and the Programme "Molécules et Cibles Thérapeutiques" CNRS-Institut National de la Santé et de la Recherche Médicale. We are grateful to P. Gaudray and E. Deval for fruitful discussion, to R. Waldmann for providing the mouse ASIC3 genomic sequence, and to M. Jodar for technical assistance.

Correspondence should be addressed to Prof. Michel Lazdunski, Institut de Pharmacologie Moléculaire et Cellulaire, Centre National de la Recherche Scientifique-Unité Mixte de Recherche 6097, 660 route des Lucioles, Sophia Antipolis, 06560 Valbonne, France. E-mail: ipmc@ipmc.cnrs.fr.

Copyright (C) 2002 Society for Neuroscience $0270-6474 / 02 / 2210662-09 \$ 15.00 / 0$
}

expressing neurons and leads to a higher sensory neuron excitability. An analysis of the promoter region of the ASIC3 encoding gene, an ASIC specifically expressed in sensory neurons and associated with chest pain that accompanies cardiac ischemia, reveals that gene transcription is controlled by NGF and serotonin.

Key words: acid-sensing ion channel; ASIC; inflammation; nociception; neuronal excitability; NGF; proinflammatory mediators; ASIC3; promoter; DRG

Tissue acidosis is an important feature of inflammation in which extracellular $\mathrm{pH}$ can drop to values as low as 5.4 (Jacobus et al., 1977). The protons are released by lysed cells along with degranulation of different mediators, or they come from a hypoxic metabolism. Acidosis has been shown to be directly linked to the feeling of pain in vivo in normal tissues and to contribute to sustained pain and hyperalgesia in inflammation (Steen and Reeh, 1993; Steen et al., 1995; Issberner et al., 1996; Reeh and Steen, 1996). Protons are one of the most effective substances for the activation of nociceptors (Steen et al., 1990, 1992).

Protons directly gate depolarizing cationic channels on sensory neurons (Krishtal and Pidoplichko, 1981; Bevan and Yeats, 1991), which correspond to the now well characterized acid-sensing ion channels (ASICs) (Waldmann et al., 1996; Waldmann and Lazdunski, 1998). Different isoforms of the ASICs arrange in homotetramers and heterotetramers to form functional channels: ASIC1a and 1b, ASIC2a and 2b, and ASIC3 (Waldmann et al., 1996; Garcia-Anoveros et al., 1997; Lingueglia et al., 1997; Waldmann et al., 1997a,b; Chen et al., 1998; Babinski et al., 2000; Benson et al., 2002). In sensory neurons, the expression of the genes coding for specific ASICs is increased in the case of inflammation, and therapeutic doses of nonsteroid antiinflammatory drugs can prevent ASIC transcription increase by inflammation (Voilley et al., 2001).

This paper reports for the first time the cloning of an ASICencoding gene promoter region. It analyzes the contributions and possible mode of action of the different inflammatory mediators responsible for the change in mRNA levels of the different ASICs and correlates this change to an increase in sensory neuron excitability through an augmentation in ASIC channel activity. These different modifications could participate in the setting of inflammatory hyperalgesia.

\section{MATERIALS AND METHODS}

Dorsal root ganglion neuron primary culture and RT-PCR experiments. Cultures were prepared, and RNA purification and RT-PCR were performed as described previously (Voilley et al., 2001) with 35 cycles 
(saturation being reached after 42 cycles). The proinflammatory and control substances tested individually (Sigma, St. Louis, MO) were incubated on the cells for 8 or $24 \mathrm{hr}$. The tested substances were as follows: $5 \mathrm{ng} / \mathrm{ml} \mathrm{IL}-1 \beta, 5 \mathrm{ng} / \mathrm{ml} \mathrm{IL-3,} 5 \mathrm{ng} / \mathrm{ml} \mathrm{IL}-6,1500 \mathrm{ng} / \mathrm{ml} \mathrm{IL-8,} 5$ $\mathrm{ng} / \mathrm{ml} \mathrm{IL}-12,5 \mathrm{ng} / \mathrm{ml}$ interferon $\gamma, 5 \mathrm{ng} / \mathrm{ml} \mathrm{TNF} \alpha, 5 \mathrm{ng} / \mathrm{ml} \mathrm{TGF} \beta, 100$ $\mathrm{ng} / \mathrm{ml} \mathrm{NGF}, 2000 \mathrm{ng} / \mathrm{ml}$ histamine, $2000 \mathrm{ng} / \mathrm{ml}$ serotonin, $1000 \mathrm{ng} / \mathrm{ml}$ bradykinin, $400 \mathrm{ng} / \mathrm{ml}$ calcitonin gene-related peptide, and $100 \mathrm{ng} / \mathrm{ml}$ substance P.

Patch-clamp recording on dorsal root ganglion sensory neurons. Ion currents were recorded using the whole-cell patch-clamp technique. Data were sampled at $500 \mathrm{~Hz}$ and low-pass filtered at $3 \mathrm{kHz}$ using pClamp8 software (Axon Instruments, Foster City, CA). The statistical significance of differences between sets of data was estimated by the singlesided Student's test. The pipette solution contained (in mM): $140 \mathrm{KCl}, 5$ $\mathrm{NaCl}, 2 \mathrm{MgCl}_{2}, 5$ EGTA, $2 \mathrm{~K}_{2} \mathrm{ATP}, 10 \mathrm{HEPES}, \mathrm{pH} 7.35$, and the bath solution contained (in mM): $150 \mathrm{NaCl}, 5 \mathrm{KCl}, 2 \mathrm{MgCl}_{2}, 2 \mathrm{CaCl}_{2}, 10$ glucose, 10 HEPES, pH 7.45. CNQX $(20 \mu \mathrm{M})$ and kynurenic acid (10 $\mu \mathrm{M})$ (Sigma) were added to inhibit glutamate-induced currents. 2-[Nmorpholino]ethanesulfonic acid was used instead of HEPES to buffer bath solution $\mathrm{pH}$ ranging from 6 to 5 . Changes in extracellular $\mathrm{pH}$ were induced by shifting one of eight outlets of a microperfusion system in front of the cell. Experiments were performed at room temperature. Bovine serum albumin $(0.1 \%)$ was added in extracellular solutions containing the spider toxin PcTX1. The toxin was applied at least $1 \mathrm{~min}$ before the $\mathrm{pH}$ drop. Capsaicin (Sigma) was used at $10 \mu \mathrm{M}$. Cultured dorsal root ganglion (DRG) neurons were treated overnight with the mixture of proinflammatory factors, and currents were recorded from a similar number of control and treated neurons. Capsaicin- and protoninduced currents were recorded on primary cultured DRG neurons $2 \mathrm{~d}$ after the enzymatic dissociation. The PcTX1 toxin was used to determine the fraction of homomeric ASIC1a current (Escoubas et al., 2000). Current densities (picoamperes per picoFarads) and proportions of neurons expressing each current type were measured from control and treated neurons from each cell culture and pulled together. Statistical analysis of the data was performed with GraphPad Prism 3.03 (GraphPad Software). Current densities showed a Gaussian distribution and were expressed as mean \pm SEM, and the significance was thus tested using the unpaired Student's $t$ test.

Transcription start site determination and promoter isolation. The transcription start site (TSS) study was done with the Smart Race cDNA amplification kit (Clontech, Cambridge, UK) on rat DRG total RNA using the indications provided by the supplier. Two PCR rounds were realized using at first the forward universal primer and the reverse 5'-CTGTTCCAGAAATACCCCAGGAC ASIC3 (GenBank accession number AF013598) primer and for the second round the forward nested universal primer and the reverse 5'-GCCGCCAGCGACAGGAGCACA ASIC3 primer. PCR products were then purified, subcloned in pCR2.1TOPO vector (Invitrogen, Gaithersburg, MD), and sequenced. The rat promoter region was obtained by PCR on genomic DNA with reverse oligonucleotides designed from ASIC3 transcript and forward ones from the 5' region of ASIC3 gene on the mouse genome (provided by R. Waldmann, Institut de Pharmacologie Moléculaire et Cellulaire). Two PCR rounds were realized (using the Taq Platinium; Invitrogen): the first round with the forward CCTAGCCTTTGTGAGAGTCT and the reverse CCGCTCAGCCACCTGGTAGAG primers, the second halfnested round with the forward CCTAGCCTTTGTGAGAGTCT and the reverse GCCGCCAGCGACAGGAGCACA primers. PCR products were then purified, cloned in pCR2.1-TOPO vector, and sequenced. With this method, $\sim 3 \mathrm{~kb}$ were cloned. In parallel, the use of a Rat Genome Walker Kit (Clontech) only allowed the isolation of a $1.5 \mathrm{~kb}$ fragment (matching with the $3^{\prime}$ end of the $3 \mathrm{~kb}$ fragment). Analysis of the DNA sequence was done with MatInspector Professional 5.2 (Quandt et al., 1995). Four deletions of the $3 \mathrm{~kb}$ sequence were realized by PCR, using Takara LA Taq polymerase. The PCR products were purified and subcloned in pBlue TOPO (Invitrogen) in the $5^{\prime}$ of the $\beta$-galactosidase reporter gene. The $3 / 2925 \Delta$ CAAT mutant consisted of the deletion of the CCAAT box matrix $(-405$ to -416$)$ generated by PCR.

Transfection and reporter gene activity measurements. Transient transfection of 1-d-old primary culture of DRG cells was performed with Exgen 500 (Euromedex), according to the supplier's protocol. pBlueTOPO vectors containing the constructs were cotransfected with a pSEAP2 vector containing the gene coding for the secreted alkaline phosphatase (SEAP) under a constitutive promoter (Clontech). After transfection, the primary cultured neurons were either left in normal medium or treated with different combinations of the following factors:
Table 1. Induction factors of the levels of ASIC transcripts measured by semiquantitative RT-PCR on DRG neurons in primary culture obtained after treatment with proinflammatory mediators

\begin{tabular}{llllll} 
& ASIC1a & ASIC1b & ASIC2b & ASIC3 & VR1 \\
\hline NGF & $4.0 \pm 0.8$ & $2.6 \pm 0.4$ & $2.7 \pm 0.4$ & $7.3 \pm 1.7$ & \\
5HT & $4.5 \pm 0.9$ & $2.9 \pm 0.5$ & $3.5 \pm 4.5$ & $9.8 \pm 2.9$ & \\
IL-1 & $6.0 \pm 3.7$ & $3.3 \pm 1.6$ & $1.5 \pm 0.7$ & $5.2 \pm 2.3$ & \\
BK & $4.5 \pm 1.2$ & $3.1 \pm 0.2$ & $3.1 \pm 0.4$ & $3.7 \pm 0.9$ & \\
Mix & $5.0 \pm 0.9$ & $2.9 \pm 0.4$ & $3.2 \pm 0.7$ & $7.8 \pm 1.5$ & $1.2 \pm 0.1$
\end{tabular}

NGF, Nerve growth factor; 5HT, serotonin; IL-1, interleukin-1b; BK, bradykinin; Mix, mix of the four compounds. Mean \pm SEM is shown; $n \geq 3$ different cell cultures with different animals.

NGF, IL-1 $\beta$, bradykinin, serotonin, or anti-NGF antibody (1:1000; Sigma). $\beta$-galactosidase activity was measured with the Galacto-Star kit (Tropix), and SEAP activity was measured with the Great EscAPe SEAP detection kit (Clontech), according to the protocols provided by the suppliers, $24 \mathrm{hr}$ after transfection and treatment. The measures were realized with a Biorbit 1253 luminometer. For each sample, the $\beta$-galactosidase activity was normalized with the SEAP activity (reflecting the transfection level) and the amount of proteins (measured with the Bio-Rad protein assay). Background level was measured with the $\beta$-galactosidase vector with no added promoter sequence. Statistical analysis was performed with Origin41. Comparison of the means was done using Student's $t$ test.

\section{RESULTS}

\section{Action of proinflammatory mediators on ASIC gene expression in DRG neurons}

We had shown previously that inflammation conditions increased in vivo the transcript levels of ASICs (Voilley et al., 2001). To find which inflammatory factors were implicated, we tested different mediators on DRG neurons in primary culture and measured the levels of ASIC mRNAs by semiquantitative RT-PCR. Among the different compounds tested (see Materials and Methods), 10 had no effect (even at concentrations $5-150 \times$ the $\mathrm{EC}_{50}$ given by the supplier), and 4 were able to mimic the increase observed in vivo: NGF, serotonin, interleukin-1, and bradykinin. The concentrations used for these four compounds (which were 2-10× the $\mathrm{EC}_{50}$ given by the supplier) were in the range of concentration usually used in the literature or based on levels found in inflamed tissues (Ristimaki et al., 1994; Bevan and Winter, 1995; Mössner and Lesch, 1998; Petersen et al., 1998; Stucky et al., 1998; Habelt et al., 2000). The induction factors ranged from 3- to 10-fold the basal expression (Table 1) for ASIC1a, -1b, -2b, and -3 . We also measured the level of the vanilloid receptor VR1 transcript, because this cation channel is also sensitive to protons (Tominaga et al., 1998) and is also an important pain sensor (McCleskey and Gold, 1999; Caterina and Julius, 2001). The level of VR1 was unchanged, as observed previously (Hu-Tsai et al., 1996; Habelt et al., 2000; Voilley et al., 2001). We thus used a mixture of NGF, serotonin, interleukin-1, and bradykinin in the following studies and referred to this mixture as the proinflammatory mix.

\section{Effects of proinflammatory mediators on $\mathrm{H}^{+}$-gated currents in DRG neurons}

Capsaicin- and proton-induced currents were recorded on primary cultured DRG neurons. The PcTX1 toxin was used to specifically inhibit homomeric ASIC1a channels (Escoubas et al., 2000). Typical recordings obtained from a neuron expressing VR1, homomeric ASIC1a, and ASIC3-like currents are shown in Figure $1 A$. The inhibition of ASIC1a current by application of PcTX1 (10 nM) revealed a biphasic ASIC3-like current activated 
A

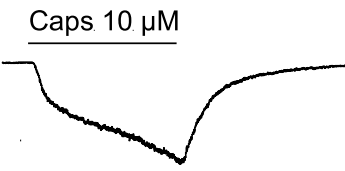

B $\square$ control

80 \% neurons

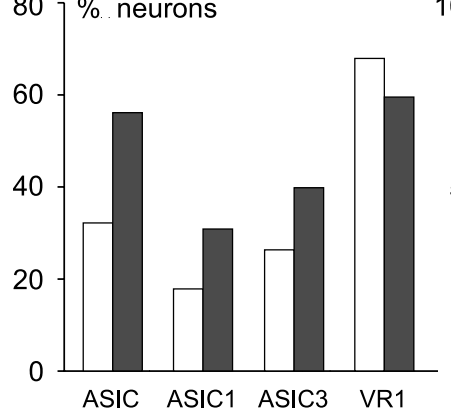

100

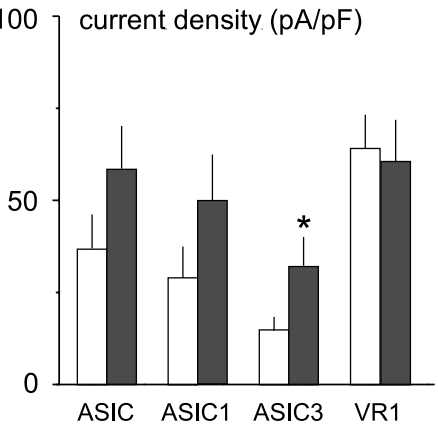

Figure 1. Effect of proinflammatory mediators on proton-gated currents in rat DRG neurons. $A$, Original current traces from a DRG neuron expressing capsaicin-activated VR1 current (left) and PcTX1-sensitive ASIC1a current and ASIC3-like current (right). This neuron was treated overnight with the proinflammatory mix. Holding potential was $-50 \mathrm{mV}$. $B$, Percentage of recorded neurons expressing an ASIC-like current ( $A S I C)$, a PcTX1-sensitive ASIC1a current (ASIC1), an ASIC3-like current (ASIC3), and a capsaicin-activated VR1 current (VR1), in control neurons (white bars) and in neurons treated overnight with the proinflammatory mix (dark gray bars). Some neurons can express a mixture of these different current types because each current type (VR1, ASIC1a, or ASIC3-like) could be found alone or associated with one or two of the others. The proportion of neurons expressing each current type, whether alone or associated with one or two other types, was determined. The total number of recorded neurons was 34 for each condition, from 5 different cell cultures in which similar numbers of control and treated neurons were recorded. $C$, Mean current density (picoamperes per picoFarads) of ASIC-like current (ASIC), PcTX1-sensitive ASIC1a current (ASIC1), ASIC3-like current (ASIC3), and capsaicin-activated VR1 current (VR1), in control neurons (white bars) and in neurons treated overnight with the proinflammatory mix (dark gray bars). Holding potential was $-50 \mathrm{mV}$; ASIC current amplitudes were measured at $\mathrm{pH}$ 5. Mean \pm SEM is shown; $n$ ranges from 8 to 23 from 5 different cell cultures. ${ }^{*} p<$ 0.05 ; significantly different from the control value.

by a $\mathrm{pH}$ drop from 7.4 to 6 . DRG neurons were highly variable in their expression of ASIC and VR1 currents. The proportion of neurons expressing the different current types was determined in control and treated neurons from each of five different cell cultures and pooled together (Fig. $1 B$ ). Treatment with the proinflammatory mix increased the number of neurons expressing an ASIC current from 32.3 to $55.8 \%$ of the recorded neurons (Fig. $1 B$, Table 2), without increasing the number of neurons expressing a capsaicin-activated current $(67.6 \%$ of control neurons; $58.8 \%$ of treated neurons). The treatment increased the proportions of neurons expressing ASIC1a or ASIC3-like currents from 17.6 to $30 \%$ and 26.5 to $38.2 \%$, respectively. This effect produced an increase in the probability of coexpression of ASIC and VR1 currents, from $11.7 \%$ in control neurons to $17.6 \%$ in treated neurons, associated with a decrease in the probability of expression of VR1 alone, from 50 to $32.3 \%$ (Table 2). Figure $1 C$ shows that the treatment with the proinflammatory mix increased the mean peak ASIC current activated at pH 5 from $36.9 \pm 10.5$ to $58.3 \pm 13.1 \mathrm{pA} / \mathrm{pF}$ without affecting the VR1 current density
Table 2. ASIC and VR1 currents on DRG neurons in primary cultures

\begin{tabular}{llllll} 
& \multicolumn{2}{l}{$\%$ Recorded neurons } & & \multicolumn{2}{l}{ Current density $(\mathrm{pA} / \mathrm{pF})$} \\
\cline { 2 - 3 } \cline { 5 - 6 } & Control & Treated & & Control & Treated \\
\hline ASIC-like & $32.3(11 / 34)$ & $55.8(19 / 34)$ & & $36.9 \pm 10.5$ & $58.3 \pm 13.1$ \\
ASIC1a & $17.6(6 / 34)$ & $30.0(10 / 34)$ & & $29.1 \pm 9.0$ & $50.0 \pm 12.4$ \\
ASIC3-like & $26.5(9 / 34)$ & $38.2(13 / 34)$ & & $15.1 \pm 3.5$ & $34.9 \pm 8.2$ \\
VR1 & $67.6(23 / 34)$ & $58.5(20 / 34)$ & & $64.2 \pm 10.1$ & $60.7 \pm 11.0$ \\
ASIC + VR1 & $11.7(4 / 34)$ & $17.6(6 / 34)$ & & \\
VR1 alone & $50.0(17 / 34)$ & $32.3(11 / 34)$ & &
\end{tabular}

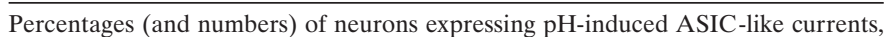
ASIC1a current (PcTx1-sensitive pH-induced current), ASIC3-like, and VR1 (capsaicin-induced) current were measured under normal conditions (control) or in neurons treated with the proinflammatory mix (values reported from Fig. 1B). The current densities were measured under the same conditions (values reported from Fig. $1 C$, as mean $\pm \mathrm{SEM}$ ). Percentages of recorded neurons expressing either both VR1 and ASIC currents or VR1 current alone are given in the second part of the table.

(Table 2). ASIC1a and ASIC3-like current densities were also increased. Even with the high variability of current density values, this effect was significant $(p<0.05)$ for the ASIC3-like current, reaching $34.9 \pm 8.2 \mathrm{pA} / \mathrm{pF}$ from the control value of $15.1 \pm 3.5$ $\mathrm{pA} / \mathrm{pF}$. The density of the sustained ASIC current was not significantly modified by the treatment and neither was the mean cell capacitance of neurons expressing an ASIC-like current (control: $35 \pm 3 \mathrm{pF}, n=37$; treated: $41 \pm 4 \mathrm{pF}, n=35$ ). A previous study showed a diminished acid-triggered transient current amplitude on DRG neurons on NGF deprivation, but without any change in the number of pH-responsive neurons (Bevan and Winter, 1995).

To estimate the effect of such an increase in ASIC3-like peak current density on neuronal excitability, membrane potential variations were recorded on neurons expressing mainly an ASIC3like current. Figure 2 presents typical recordings from two neurons expressing only an ASIC3-like current insensitive to the PcTX1 toxin (10 nM; data not shown) and no capsaicin-induced current (shown for the treated neuron) (Fig. 2B). These sensory neurons had a resting potential at approximately $-58 \mathrm{mV}$, which was not significantly different between control and treated neurons (control: $-57.4 \pm 2.6 \mathrm{mV}, n=15$; treated: $-59.8 \pm 3.0 \mathrm{mV}$, $n=9$ ), and no spontaneous action potentials (APs). A pH drop from 7.4 to 6 induced a biphasic depolarization, with a transient and a plateau phase, which is compatible with the kinetics of the ASIC3-like current (Fig. 2A,B). However, effects of $\mathrm{pH}$ on other ionic channels that could also contribute to membrane potential changes cannot be ruled out. Interestingly, no APs were triggered during the plateau of the depolarization, even for small $\mathrm{pH}$ drops, contrary to what was reported in hippocampal neurons (Baron et al., 2002). The transient depolarization induced by $\mathrm{pH} 6$ could trigger bursts of APs in the neuron treated by the proinflammatory mix, as shown in enlargements in Figure $2 B$, whereas the AP threshold was not reached by the transient depolarization induced by $\mathrm{pH}$ 6.6. In the control neuron (Fig. $2 A$ ), the membrane depolarization induced by the smaller ASIC3-like current could not trigger any action potential, even at $\mathrm{pH}$ 6. This increase in excitability after treatment with the proinflammatory mix was not caused by a shift in the ASIC3-like current $\mathrm{pH}$ dependency, which was not different in control and treated neurons (Fig. 2C). The mean depolarization induced by the $\mathrm{pH}$ drop was increased in treated neurons for each $\mathrm{pH}$ value (Fig. 2D). The mean AP threshold (Fig. 2D, gray bar) was not significantly different for control $(-25.4 \pm 2.6 \mathrm{mV} ; n=11)$ and treated neurons $(-29.8 \pm$ 

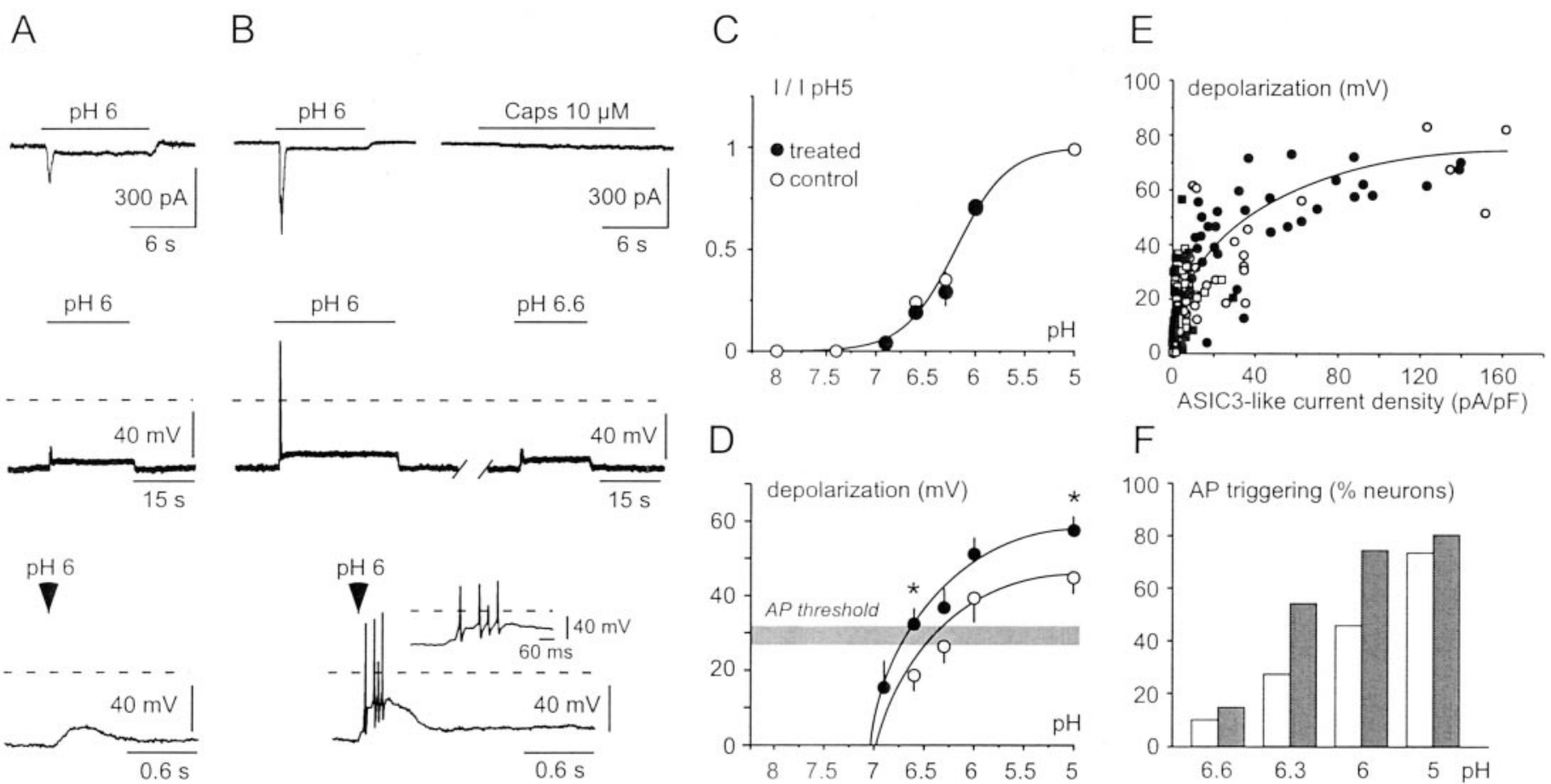

\section{$\mathrm{F}$}

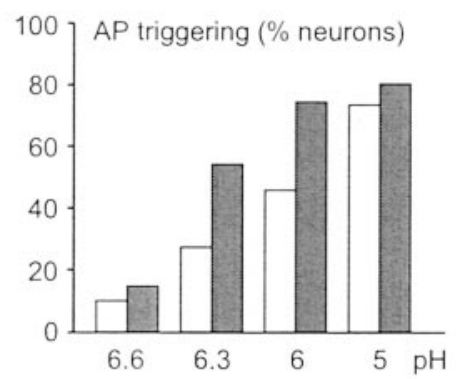

Figure 2. Effect of the proinflammatory mediators on the excitability of DRG neurons containing an ASIC3-like current. $A$, Original current and potential recordings from a control DRG neuron. Top, Voltage-clamp recording of ASIC3-like current induced by a $\mathrm{pH}$ drop from 7.4 to 6 , whereas capsaicin induced no VR1 current (data not shown). Holding potential was $-50 \mathrm{mV}$. Middle, Current-clamp recording $(I=0 \mathrm{pA})$ of the depolarization induced by a pH drop from 7.4 to 6 . No action potential was triggered by the membrane depolarization. The dashed line represents the $0 \mathrm{mV}$ level. Bottom, Enlargement of the initial depolarization induced by the $\mathrm{pH}$ drop. $B$, Original current and potential recordings from a proinflammatory mix-treated DRG neuron. Top, Voltage-clamp recording of ASIC3-like current induced by $\mathrm{pH}$ drop from 7.4 to 6, whereas capsaicin induced no VR1 current (right). Holding potential was $-50 \mathrm{mV}$. Middle, Current-clamp recording $(I=0 \mathrm{pA})$ of the depolarization induced by a $\mathrm{pH}$ drop from 7.4 to 6 and 6.6 . Action potentials were triggered by the membrane depolarization induced by $\mathrm{pH} 6$ but not by $\mathrm{pH}$ 6.6. Bottom, Enlargement of the initial depolarization induced by the $\mathrm{pH}$ drop, showing action potential bursts. $C, \mathrm{pH}$-dependent activation of the peak ASIC3-like current in control $(O)$ and treated $(\bullet)$ neurons. Holding potential was $-50 \mathrm{mV}$. The current amplitude was expressed as a fraction of the current induced by $\mathrm{pH} 5(\mathrm{I} / \mathrm{I} \mathrm{pH} 5)$ and plotted as mean \pm SEM; $n$ ranges from 5 to 19 . The data could be fitted by a sigmoid with a $\mathrm{pH}_{0.5}=6.2$ and a Hill slope factor of 1.7. $D$, Mean peak membrane depolarization as a function of extracellular $\mathrm{pH}$ in control $(\bigcirc)$ and treated $(\bullet)$ neurons, measured from current-clamp recordings $(I=0 \mathrm{pA})$. The resting potential was $-57.4 \pm 2.6 \mathrm{mV}(n=15)$ and $-59.8 \pm 3.0 \mathrm{mV}(n=9)$ in control and treated neurons, respectively. The depolarization values during APs were excluded from measurements. The membrane potential area corresponding to the AP threshold is indicated by a gray bar (see Results for value). Mean \pm SEM values are shown; $n$ ranges from 4 to $19 .{ }^{*} p<0.05$; significantly different from the control value. $E$, Membrane depolarization as a function of ASIC3-like current density activated by the same $\mathrm{pH}$ drop on the same neuron. The membrane potential was measured by current-clamp $(I=0 \mathrm{pA})$, and the depolarization values during APs were excluded from measurements. ASIC3-like current density (picoamperes per picoFarads) was subsequently measured on the same neuron, at a holding potential similar to the resting potential measured in current clamp $(I=0)$. Membrane potential and ASIC3-like current density were measured during the transient peak $(\bigcirc$, control; $\bullet$, treated neurons) and during the sustained plateau phase ( $\square$, control; $\square$, treated neurons) for the same $\mathrm{pH}$ value. $F$, Percentage of recorded neurons in which APs were triggered by various $\mathrm{pH}$ drops (white bars, control; dark gray bars, treated neurons).

$2.4 \mathrm{mV} ; n=10)$; neither was the relationship between the ASIC3-like current density and the membrane depolarization induced by the same $\mathrm{pH}$ drop on the same neuron (Fig. 2E). Thus, the increase in neuronal excitability induced by the proinflammatory mix appeared to be related to the increase in ASIC3like current amplitude and in the subsequent depolarization that triggers APs when reaching the threshold value. Indeed, the number of neurons in which APs could be triggered by a $\mathrm{pH}$ drop was increased by the proinflammatory mix treatment (Fig. $2 F$ ), particularly for small $\mathrm{pH}$ changes activating submaximal ASIC3like currents that depolarized the neuron near the AP threshold (Fig. 2D). A pH drop from 7.4 to 6.3 triggered APs in $54.5 \%$ of the treated neurons compared with $27.3 \%$ of the control neurons, whereas a pH drop from 7.4 to 6 triggered APs in $75 \%$ of the treated neurons compared with $46 \%$ of the control neurons. Thus, our results clearly show that a higher ASIC3 transcript level is accompanied by a higher ASIC3 current amplitude leading to higher neuronal excitability.

\section{Regulation by proinflammatory mediators of ASIC3 promoter region activity}

To determine the transcription start site of the ASIC3 encoding gene, we performed $5^{\prime}$ rapid amplification of cDNA ends (RACE)-PCR on RNA from rat DRGs. The longest fragment obtained was 343 nucleotides long from the ATG. It could correspond to the transcription start site. Smaller fragments were also obtained, suggesting more proximal start points or strong secondary structures in the $5^{\prime}$ noncoding region of the mRNA. Whether the RNA was extracted from normal DRGs or from DRGs under inflammatory conditions [from an animal under a Complete Freund's adjuvant (CFA)-induced inflammation], the sizes of the fragments obtained were similar. This means that the same promoter region is used in both conditions. We then used rat genomic DNA to isolate the promoter region of the gene. We cloned a $3174 \mathrm{bp}$ fragment upstream of the ATG. This sequence appeared in GenBank under accession number AF527175. The 


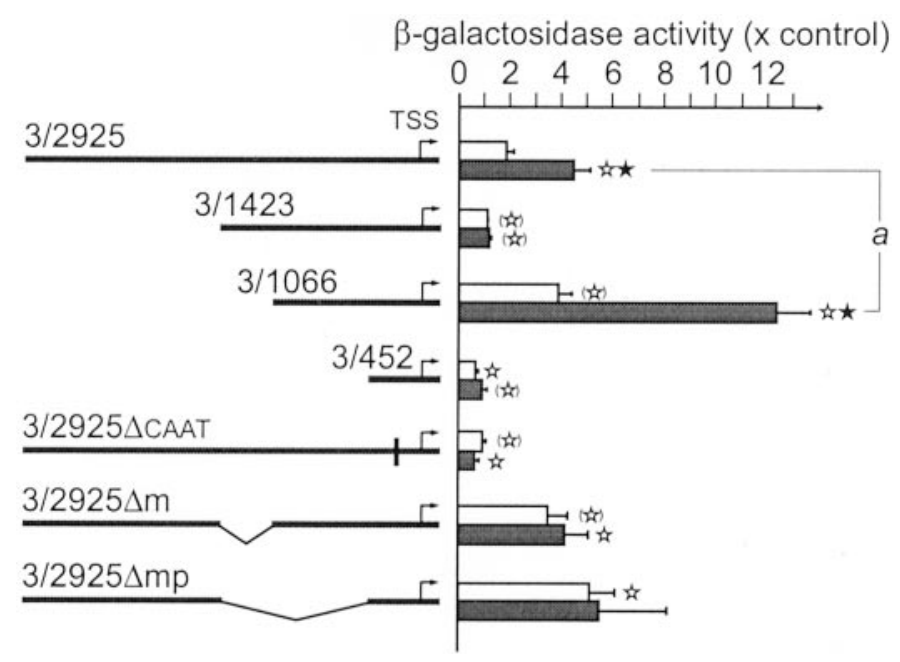

Figure 3. ASIC3 gene promoter region study by reporter gene assays. The activities of different constructs of the promoter region of the ASIC3 gene were tested using $\beta$-galactosidase as a reporter gene. The clones were transfected into DRG neurons in primary culture, and the cells were either maintained in the regular medium (white bars) or treated with the proinflammatory mix (NGF, bradykinin, IL-1, and serotonin) (dark gray bars) shown to mimic inflammation action on ASIC encoding gene transcription. NGF antibody corresponds to incubation with the anti-NGF antibody. Results are normalized on SEAP activity (which takes into account the transfection yield) and the amount of proteins. They are expressed as the ratio of a treated condition with the background level (given by the $\beta$-galactosidase vector basal activity; i.e., without any promoter region insert added) and are given as mean \pm SEM. The following constructs were studied: the full-length sequence of ASIC 3 encoding gene promoter region (the 2925-base long fragment, named 3/2925, from -249 to -3174$)$, three shorter fragments $(3 / 1423$, from -249 to $-1672 ; 3 / 1066$, from -249 to -1315 ; and $3 / 452$, from -249 to -701 ), and three deletion fragments $(3 / 2925 \Delta C A A T$, lacking the putative CCAAT box from -405 to $-416 ; 3 / 2925 \Delta m$, lacking from -1315 to $-1672 ; 3 / 2925 \Delta m p$, lacking from -701 to -1672 ). $n \geq 3$; $\star$ corresponds to a significant difference $(p<0.05)$ between the control and the treated conditions for the same clone, is corresponds to a significant difference $(p<0.05)$, and ( corresponds to a difference with $p<0.1$, between the control of clone $3 / 2925$ and any other condition.

analysis of this fragment revealed no TATA box, no initiator element (Inr), and no GC box, but several CCAAT boxes along the sequence. The most probable CCAAT box corresponded to an inverted nonconsensus box at -62 bp from the TSS $(-405$ from the ATG). In TATA-less promoters with inverted CCAAT box, the functional site is found at the average position of $-63 \pm$ 29 to the TSS (Mantovani, 1998). The 343-base 5' untranslated region (UTR) of the mRNA was compared with the genomic sequence. It contained no intron, and the possibility of multiple transcription start sites was highly probable because many TATAless promoters lacking initiator elements use multiple start sites, and the 5' UTR contains a multiple start site element downstream-1-like sequence, named MED-1, an element necessary for multiple start utilization, at position -305 from the ATG (Ince and Scotto, 1995). A 2925 bp DNA fragment (from - 249 to -3174 from the ATG) and different deletion constructs obtained from this fragment were subcloned before the $\beta$-galactosidase reporter gene and transfected into primary cultures of DRG neurons along with a SEAP-containing vector.

Figure 3 shows the results regarding the activities of different parts of the promoter region in control medium and with the proinflammatory mix. The full-length sequence of the ASIC3 promoter region $3 / 2925$ conferred a basal activity that was signif- icantly increased by proinflammatory mediators (the $\beta$-galactosidase activity augmented from $1.9 \pm 0.4$ to $4.6 \pm 1.0 ; p<0.05)$. When the putative inverted CCAAT box within the complete clone was deleted (construct $3 / 2925 \Delta C A A T$ ), there was a total loss of the transcriptional activity (i.e., to the background level, which corresponds to the activity of the $\beta$-galactosidase vector with no added promoter sequence), showing the importance of this element in ASIC3 encoding gene transcription. The shorter construct 3/1423 displayed an activity in the range of the background level both in normal and in treated conditions. This activity seemed lower than the basal activity of the full-length promoter region $(1.2 \pm 0.1$ vs $1.9 \pm 0.4 ; p=0.1)$. Construct $3 / 1066$ displayed basal activity that was twofold higher than that of construct $3 / 2925(4.0 \pm 0.6$ compared with $1.9 \pm 0.4 ; p=0.07)$ and four times higher than the background level. Treatment with the proinflammatory mix multiplied its basal activity by 3 (from $4.0 \pm 0.6$ to $12.2 \pm 1.4 ; p=0.002$ ), bringing a 12 -fold increase from the background level. The proinflammatory mix-induced activity of construct 3/1066 was approximately three times higher than that of construct $3 / 2925$ under the same conditions $(12.2 \pm$ 1.4 compared with $4.6 \pm 1.0 ; p=0.006)$. Construct $3 / 1066$ basal activity was not significantly different from construct $3 / 2925$ induced activity $(4.0 \pm 0.6$ compared with $4.6 \pm 1.0)$. The shortest construct $3 / 452$ had a control activity significantly lower than construct $3 / 2925(0.7 \pm 0.2$ vs $1.9 \pm 0.4 ; p=0.02)$, which had an activity corresponding to the background level, and the proinflammatory mix did not induce any change. Activities of construct $3 / 2925 \Delta \mathrm{m}$, which lacked the middle fragment, -1315 to -1672 , were similar in control conditions $(3.5 \pm 0.8)$ and after the proinflammatory treatment $(4.0 \pm 0.8)$ and corresponded to the maximal activity of the full-length clone 3/2925. Construct $3 / 2925 \Delta \mathrm{mp}$, lacking the sequence from -701 to -1672 , showed comparable activities in control and inflammatory conditions (basal: $5.2 \pm 1.0$; treated: $5.0 \pm 2.0$ ).

These results indicate that different parts of the promoter region have different functional roles in the basal transcription of the ASIC3 encoding gene and the presence of inflammatory mediators.

We then tested the proinflammatory factors individually on the constructs displaying a transcriptional activity (Fig. 4). On the full-length clone $3 / 2925$, NGF alone was sufficient to induce a maximal expression almost tripling the activity $(4.9 \pm 1.0 \mathrm{vs} 1.9 \pm$ $0.4 ; p=0.04)$. The addition of anti-NGF antibodies, which blocked the NGF present in the culture medium or produced by the cells in culture, induced a decrease of the basal activity to the background level (a reduction from $1.9 \pm 0.4$ to $0.6 \pm 0.1 ; p=$ 0.01). The total induction of ASIC3 encoding gene transcription by NGF represented then an eightfold increase and was in the same range as the mRNA level induction measured by RT-PCR (7.3 \pm 1.3-fold) (Table 1). Serotonin, bradykinin, and interleukin-1 had no effect on 3/2925 expression. Construct $3 / 1066$ showed a different pattern of activity. Serotonin was able to fully activate its expression (from $4.0 \pm 0.6$ to $9.7 \pm 2.2 ; p=$ 0.05 ), but in a NGF-dependent manner, because anti-NGF antibodies completely abolished serotonin action. However, the simultaneous addition of NGF, which had no enhancing activity alone, along with serotonin, prevented serotonin action. Bradykinin and IL-1 had no action on 3/1066 expression. Construct $3 / 2925 \Delta \mathrm{m}$ and construct 3/2925 $\mathrm{mp}$ showed comparable expression profiles. Their expression level was the same as the basal level of construct $3 / 1066$, with or without proinflammatory mediators. The addition of anti-NGF antibodies tended to decrease 


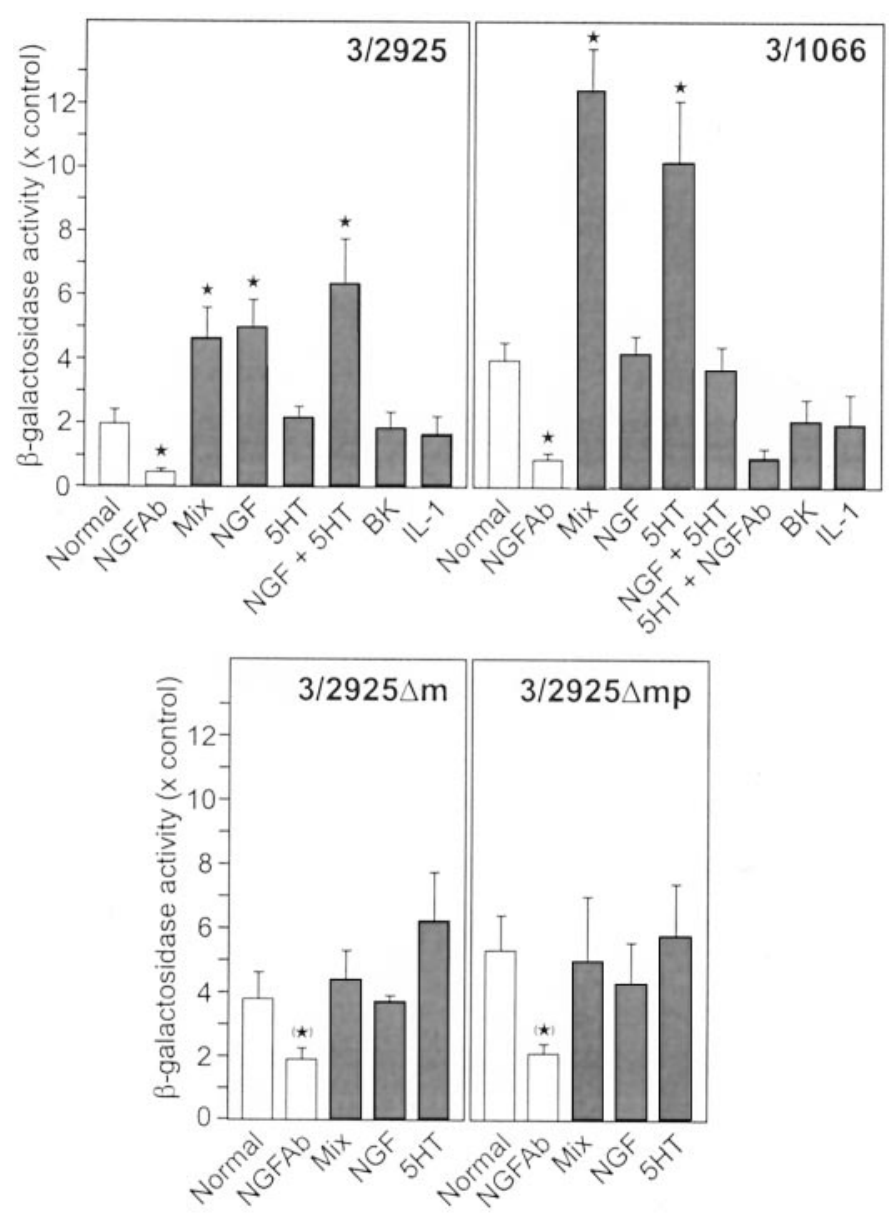

Figure 4. Effects of the different active proinflammatory mediators on ASIC3 encoding gene transcription. The same constructs as in Figure 3 are tested in the same system with the mediators used individually. Results are given as in Figure 3 (mean \pm SEM) with $n \geq 3$. $\star$ corresponds to a significant difference $(p<0.05)$, and $(\star)$ corresponds to a difference with $p<0.1$, between the control and the treated conditions for the same clone. NGFAb, NGF antibody; $B K$, bradykinin; $5 H T$, serotonin.

the basal level (from $3.5 \pm 0.8$ to $1.8 \pm 0.4, p=0.1$, for construct $3 / 2925 \Delta \mathrm{m}$; from $5.2 \pm 1.0$ to $2.1 \pm 0.3$ for construct $3 / 2925 \Delta \mathrm{mp}$, $p=0.06)$.

\section{DISCUSSION}

Extracellular acidification is an important factor in inflammatory pain and hyperalgesia (Steen et al., 1990; Issberner et al., 1996; Reeh and Steen, 1996; Sutherland et al., 2000). The main $\mathrm{H}^{+}$ sensors are the ASICs (Waldmann et al., 1997a; Waldmann and Lazdunski, 1998; McCleskey and Gold, 1999). They are expressed in DRG sensory neurons and particularly in nociceptors (Chen et al., 1998; Olson et al., 1998; Petruska et al., 2000; Garcia-Anoveros et al., 2001; Voilley et al., 2001). They are strong candidates for acid-evoked nociceptive responses and especially for cardiac nociception associated with ischemia (Sutherland et al., 2001). They may also be involved in mechanosensation (Price et al., 2001).

\section{Heterogeneity of sensory neurons expressing $\mathbf{H}^{+}$-gated currents}

We have found that $32.3 \%$ of DRG neurons express an ASIC current, $17.6 \%$ express an ASIC1a current, 26.5\% express an ASIC3-like current, and $67.6 \%$ express a VR1 current, each current type being expressed either alone or associated with one or two of the others. A mixture of an ASIC1a and an ASIC3-like current is present in $9 \%$ of the neurons, which represents almost one-third of ASIC-expressing neurons, whereas a VR1 current is coexpressed with an ASIC current in $11.7 \%$ of the neurons, which represents approximately one-half of the ASIC-expressing neurons. Petruska and colleagues (2000) reported similar results, with $28 \%$ of ASIC-like-expressing neurons and $47 \%$ of VR1expressing neurons, but these authors reported a lower proportion of ASIC3-like-expressing neurons (8\%) and no coexpression of ASIC-like current and VR1 current. Taken together, all of these results indicate a functional diversity of $\mathrm{H}^{+}$-gated currents in rat DRG neurons and suggest a functional specialization of sensory fibers depending on their $\mathrm{H}^{+}$-gated channel expression pattern.

\section{Effect of proinflammatory mediators on $\mathrm{H}^{+}$-gated channels in DRG neurons}

We had shown previously that ASIC transcript levels in sensory neurons were increased in inflammatory conditions in vivo (Voilley et al., 2001). Among the large panel of mediators that we tested and that come into play in such conditions, we have shown that NGF, serotonin, bradykinin, and IL-1 are the only factors that are able to increase ASIC mRNA levels. It is well known that these locally released proinflammatory factors can activate and sensitize sensory neurons and produce hyperalgesia (Ferreira et al., 1988; Taiwo and Levine, 1992; Lewin and Mendell, 1993; Watkins et al., 1994; Dray, 1995; McMahon, 1996). NGF induces strong and long-lasting changes in sensory neurons through regulation of gene expression (Zur et al., 1995; McMahon, 1996; Woolf, 1996; Fitzgerald and Dolphin, 1997; Petersen et al., 1998; Waxman et al., 1999a). Serotonin and IL-1 induce the expression of inflammation-associated genes (Ristimaki et al., 1994; Stroebel and Goppelt-Struebe, 1994; Dinarello, 1996; Humblot et al., 1997). We have shown that in the same conditions a mix of these inflammatory mediators does not change VR1 mRNA levels.

When DRG neurons are submitted to proinflammatory mediators, there is an increase both in the ASIC current density ( $\sim 1.6$-fold) and in the proportion of neurons expressing ASIC currents (1.7-fold). Both ASIC1a and ASIC3-like current densities are increased ( $\sim 1.7$-fold and 2.3-fold, respectively), as are proportions of ASIC1a- and ASIC3-expressing neurons $(\sim 1.7$ fold and 1.4-fold, respectively). The density of capsaicin-induced (VR1) current and the proportion of neuronal cells expressing this channel type were essentially the same in control and treated conditions. These changes in ASIC expression are expected to facilitate $\mathrm{H}^{+}$-induced excitation of ASIC-expressing sensory neurons as well as induce an acid $\mathrm{pH}$ sensitivity of newly ASICexpressing neurons.

\section{Correlation between stimulated ASIC3 expression and neuronal excitability}

The increase in ASIC current densities and in ASIC-expressing cell proportion by proinflammatory mediators directly modifies the excitability of DRG neurons expressing an ASIC current.

In DRG neurons, the biphasic ASIC3-like current triggers a biphasic depolarization. APs are induced only on the peak phase and not on the plateau of ASIC3-induced depolarization. Actually, both tetrodotoxin (TTX)-sensitive and TTX-resistant voltage-dependent $\mathrm{Na}^{+}$channels are involved in the control of the excitability of sensory neurons (Rush et al., 1998; Gold, 1999; Baker and Wood, 2001) and could be recruited during extracel- 
lular acidification-induced depolarization. It is interesting to note that although the relation between the current densities and the depolarization is the same for the peak and the plateau phases, APs are triggered only by the peak in DRG neurons. This is different from what occurs in the hippocampus, where a similar relation exists but where APs appear on both the peak and the plateau phases (Baron et al., 2002). This reinforces the role of the TTX-resistant $\mathrm{Na}^{+}$channels that are expressed exclusively in sensory neurons and not in the CNS (Gold, 1999). Indeed, TTXresistant channels activate and inactivate with higher membrane potential thresholds than TTX-sensitive channels. For example, $>95 \%$ of TTX-sensitive channels are inactivated by potentials more positive than $-40 \mathrm{mV}$, whereas $>90 \%$ of TTX-resistant channels are still available at $-40 \mathrm{mV}$ (Rush et al., 1998).

The amplitude of the depolarization induced by ASIC3 currents follows a nonlinear saturating relation. Thus, a small current (for example $40 \mathrm{pA} / \mathrm{pF}$, which is only one-fourth of the maximal current in these experiments) (Fig. $2 E$ ) is able to induce an almost maximal depolarization of $\sim 50 \mathrm{mV}$, which brings the neuron membrane potential to $0 \mathrm{mV}$ and is mostly sufficient to trigger APs. The consequence is that small ASIC3 currents triggered by changes to $\mathrm{pH}$ values between 7 and 6 would bring the membrane potential in the range of the AP triggering threshold. Thus, a moderate change of these ASIC3 currents will have major consequences on neuronal excitability and AP triggering. By inducing a greater depolarization, the increase of current density by the proinflammatory mediators can double the number of APs triggered at $\mathrm{pH} 6.3$ without changing the resting potential, the AP-triggering threshold, or the current density/depolarization relation. Clearly, a same external acidification will have more impact on neuron excitability after sensory cells have been exposed to proinflammatory mediators. ASIC channels can thus be important in inflammatory hyperalgesia through the hypersensitivity to acid that we have observed in nociceptors. In addition to this effect on neuronal excitability, proinflammatory mediators also increase the proportion of ASIC-expressing neurons. This increase in $\mathrm{pH}$-responding cell number can participate in allodynia. ASIC channels are not the only ion channels that are modified in inflammatory conditions and by inflammatory mediators (like NGF). Voltage-dependent $\mathrm{Na}^{+}$and $\mathrm{Ca}^{2+}$ channels were also shown to be upregulated (Zur et al., 1995; Fitzgerald and Dolphin, 1997; Waxman et al., 1999a,b).

\section{Regulation of ASIC3 gene promoter activity by proinflammatory mediators}

ASIC3 is a particularly important ion channel for nociception (McCleskey and Gold, 1999; Sutherland et al., 2001; Chen et al., 2002). We have now shown that inflammatory mediators directly modulate ASIC3 encoding gene expression through its promoter region. This particular region is controlled by an essential inverted CCAAT box and can be divided into three main domains.

The transcription start site proximal domain confers a high basal expression of ASIC3 through endogenously produced NGF. It also confers a high potential of regulation by the proinflammatory mediator serotonin, which is the only factor to induce a maximal expression, through an NGF-dependent mechanism. A basal activity attributable to endogenous NGF is necessary for serotonin action (Fig. 4, 3/1066) because this action is suppressed by anti-NGF antibody treatment. Addition of NGF in higher concentrations along with serotonin prevents the serotonininducing action as if the two proinflammatory mediators were competing for a common intermediate element in their transduc- tion pathway. This result suggests that different mechanisms, which remain to be identified, regulate basal and stimulated expression associated with different levels of NGF.

The middle domain completely suppresses the transcriptional activity of the proximal domain. When it is removed, none of the inflammatory mediators can have an inducing action on the ASIC3 encoding gene expression, but the basal activity is high

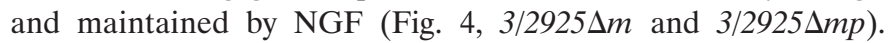
When the distal domain is present, which corresponds to the in vivo situation, some transcriptional activity is regained by the action of NGF. This factor has a low basal action and alone can enhance the expression, which, however, can only reach the basal level observed with the proximal domain alone. Numerous putative responsive elements can be detected in the ASIC3 promoter region. A detailed study will be necessary to better identify the sites and the transcription factors implicated.

Proinflammatory mediators like NGF and serotonin can thus directly enhance the transcriptional activity of the ASIC3 encoding gene. The silencing role of the middle domain would be to limit an overexpression of ASIC3 to allow its regulation by proinflammatory mediators and the subsequent increase in neuronal excitability. Conversely, VR1 expression was shown to be maximal at physiological levels of NGF (Hu-Tsai et al., 1996; Szallasi and Blumberg, 1999), and indeed we observed no further increase in VR1 transcript level and current density induced by proinflammatory mediators (Fig. 1C, Tables 1, 2). ASICs thus appear to be better candidates than VR1 to underlie the welldescribed hypersensitization of sensory neurons during inflammation (Rang et al., 1991; Cesare and McNaughton, 1997; Woolf and Costigan, 1999).

Bradykinin and IL-1 have no effect on ASIC3 gene promoter activity. This result seems surprising because the RT-PCR results have shown an increase in ASIC3 mRNA level after bradykinin or IL-1 treatment. We suggest that these mediators act on the half-life of the transcripts, as it has been described for the regulation of cyclooxygenase-2 by IL-1 (Ristimaki et al., 1994). It is noteworthy that the $3^{\prime}$ UTR of ASIC3 mRNA, which is only 87 bases long before the polyA tail, contains a predicted stem loop formed by 54 bases (a hairpin of 20 bases long, with two small loops). This stable structure could participate in the regulation of mRNA stability (Pesole et al., 2000; Putland et al., 2002).

\section{CONCLUSIONS}

This work shows that NGF and to a lesser extent serotonin are key elements for both the basal expression and the transcriptional regulation of the ASIC3 encoding gene. Endogenous NGF is known to participate in the determination of the sensitivity of primary afferent nociceptors (Bennett et al., 1998), and we now demonstrate that it allows basal ASIC3 expression in these sensory neurons. An increase in NGF level, similar to what happens during inflammation (McMahon, 1996), enhances ASIC3 encoding gene expression. This effect is directly correlated to an increase (1) in ASIC current amplitude in sensory neurons, (2) in the number of ASIC-expressing neurons, and (3) in neuronal excitability. The important role of NGF in the onset of inflammation-induced hyperalgesia and sensitization of the nociceptive system suggests that reducing NGF concentration or blocking its effect could provide a clinical advantage in some inflammatory pain states (Djouhri et al., 2001). 


\section{REFERENCES}

Babinski K, Catarsi S, Biagini G, Seguela P (2000) Mammalian ASIC2a and ASIC3 subunits co-assemble into heteromeric proton-gated channels sensitive to $\mathrm{Gd}^{3+}$. J Biol Chem 275:28519-28525.

Baker MD, Wood JN (2001) Involvement of $\mathrm{Na}^{+}$channels in pain pathways. Trends Pharmacol Sci 22:27-31.

Baron A, Waldmann R, Lazdunski M (2002) ASIC-like, protonactivated currents in rat hippocampal neurons. J Physiol (Lond) 539:485-494.

Bennett DL, Koltzenburg M, Priestley JV, Shelton DL, McMahon SB (1998) Endogenous nerve growth factor regulates the sensitivity of nociceptors in the adult rat. Eur J Neurosci 10:1282-1291.

Benson CJ, Xie J, Wemmie JA, Price MP, Henss JM, Welsh MJ, Snyder PM (2002) Heteromultimers of DEG/ENaC subunits form $\mathrm{H}^{+}$-gated channels in mouse sensory neurons. Proc Natl Acad Sci USA 99:2338-2343.

Bevan S, Winter J (1995) Nerve growth factor (NGF) differentially regulates the chemosensitivity of adult rat cultured sensory neurons. J Neurosci 15:4918-4926.

Bevan S, Yeats J (1991) Protons activate a cation conductance in a sub-population of rat dorsal root ganglion neurones. J Physiol (Lond) 433:145-161.

Caterina MJ, Julius D (2001) The vanilloid receptor: a molecular gateway to the pain pathway. Annu Rev Neurosci 24:487-517.

Cesare P, McNaughton P (1997) Peripheral pain mechanisms. Curr Opin Neurobiol 7:493-499.

Chen CC, England S, Akopian AN, Wood JN (1998) A sensory neuronspecific, proton-gated ion channel. Proc Natl Acad Sci USA 95:10240-10245.

Chen CC, Zimmer A, Sun WH, Hall J, Brownstein MJ (2002) A role for ASIC3 in the modulation of high-intensity pain stimuli. Proc Natl Acad Sci USA 99:8992-8997.

Dinarello CA (1996) Biologic basis for interleukin-1 in disease. Blood 87:2095-2147.

Djouhri L, Dawbarn D, Robertson A, Newton R, Lawson SN (2001) Time course and nerve growth factor dependence of inflammationinduced alterations in electrophysiological membrane properties in nociceptive primary afferent neurons. J Neurosci 21:8722-8733.

Dray A (1995) Inflammatory mediators of pain. $\mathrm{Br} \mathrm{J}$ Anaesth 75:125-131.

Escoubas P, De Weille JR, Lecoq A, Diochot S, Waldmann R, Champigny G, Moinier D, Menez A, Lazdunski M (2000) Isolation of a tarantula toxin specific for a class of proton-gated $\mathrm{Na}+$ channels. J Biol Chem 275:25116-25121.

Ferreira SH, Lorenzetti BB, Bristow AF, Poole S (1988) Interleukin-1 beta as a potent hyperalgesic agent antagonized by a tripeptide analogue. Nature 334:698-700.

Fitzgerald EM, Dolphin AC (1997) Regulation of rat neuronal voltagedependent calcium channels by endogenous p21-ras. Eur J Neurosci 9:1252-1261.

Garcia-Anoveros J, Derfler B, Neville-Golden J, Hyman BT, Corey DP (1997) $\mathrm{BNaC} 1$ and $\mathrm{BNaC} 2$ constitute a new family of human neuronal sodium channels related to degenerins and epithelial sodium channels. Proc Natl Acad Sci USA 94:1459-1464.

Garcia-Anoveros J, Samad TA, Zuvela-Jelaska L, Woolf CJ, Corey DP (2001) Transport and localization of the DEG/ENaC ion channel $\mathrm{BNaC} 1 \alpha$ to peripheral mechanosensory terminals of dorsal root ganglia neurons. J Neurosci 21:2678-2686.

Gold MS (1999) Tetrodotoxin-resistant $\mathrm{Na}^{+}$currents and inflammatory hyperalgesia. Proc Natl Acad Sci USA 96:7645-7649.

Habelt C, Kessler F, Distler C, Kress M, Reeh PW (2000) Interactions of inflammatory mediators and low $\mathrm{pH}$ not influenced by capsazepine in rat cutaneous nociceptors. NeuroReport 11:973-976.

Humblot N, Esteve L, Burgun C, Aunis D, Zwiller J (1997) 5-Hydroxytryptamine induces TIS8/egr-1 and c-fos expression in PC12 cells. Involvement of tyrosine protein phosphorylation. Eur J Neurosci 9:84-92.

Hu-Tsai M, Woolf C, Winter J (1996) Influence of inflammation or disconnection from peripheral target tissue on the capsaicin sensitivity of rat dorsal root ganglion sensory neurones. Neurosci Lett 203:119122

Ince TA, Scotto KW (1995) A conserved downstream element defines a new class of RNA polymerase II promoters. J Biol Chem 270:30249-30252.

Issberner U, Reeh PW, Steen KH (1996) Pain due to tissue acidosis: a mechanism for inflammatory and ischemic myalgia? Neurosci Lett 208:191-194.

Jacobus WE, Taylor GJ, Hollis DP, Nunnally RL (1977) Phosphorus nuclear magnetic resonance of perfused working rat hearts. Nature 265:756-758

Krishtal OA, Pidoplichko VI (1981) Receptor for protons in the membrane of sensory neurons. Brain Res 214:150-154.

Lewin GR, Mendell LM (1993) Nerve growth factor and nociception. Trends Neurosci 16:353-359.
Lingueglia E, de Weille JR, Bassilana F, Heurteaux C, Sakai H, Waldmann R, Lazdunski M (1997) A modulatory subunit of acid sensing ion channels in brain and dorsal root ganglion cells. J Biol Chem 272:29778-29783.

Mantovani R (1998) A survey of 178 NF-Y binding CCAAT boxes. Nucleic Acids Res 26:1135-1143.

McCleskey EW, Gold MS (1999) Ion channels of nociception. Annu Rev Physiol 61:835-856.

McMahon SB (1996) NGF as a mediator of inflammatory pain. Philos Trans R Soc Lond B Biol Sci 351:431-440.

McMahon SB, Lewin GR, Wall PD (1993) Central hyperexcitability triggered by noxious inputs. Curr Opin Neurobiol 3:602-610.

Mössner R, Lesch KP (1998) Role of serotonin in the immune system and in neuroimmune interactions. Brain Behav Immun 12:249-271.

Neumann S, Doubell TP, Leslie T, Woolf CJ (1996) Inflammatory pain hypersensitivity mediated by phenotypic switch in myelinated primary sensory neurons. Nature 384:360-364.

Olson TH, Riedl MS, Vulchanova L, Ortiz-Gonzalez XR, Elde R (1998) An acid sensing ion channel (ASIC) localizes to small primary afferent neurons in rats. NeuroReport 9:1109-1113.

Pesole G, Grillo G, Larizza A, Liuni S (2000) The untranslated regions of eukaryotic mRNAs: structure, function, evolution and bioinformatic tools for their analysis. Brief Bioinform 1:236-249.

Petersen M, Segond von Banchet G, Heppelmann B, Koltzenburg M (1998) Nerve growth factor regulates the expression of bradykinin binding sites on adult sensory neurons via the neurotrophin receptor p75. Neuroscience 83:161-168.

Petruska JC, Napaporn J, Johnson RD, Gu JG, Cooper BY (2000) Subclassified acutely dissociated cells of rat DRG: histochemistry and patterns of capsaicin-, proton-, and ATP-activated currents. J Neurophysiol 84:2365-2379.

Price MP, McIlwrath SL, Xie J, Cheng C, Qiao J, Tarr DE, Sluka KA, Brennan TJ, Lewin GR, Welsh MJ (2001) The DRASIC cation channel contributes to the detection of cutaneous touch and acid stimuli in mice. Neuron 32:1071-1083.

Putland RA, Sassinis TA, Harvey JS, Diamond P, Coles LS, Brown CY, Goodall GJ (2002) RNA destabilization by the granulocyte colonystimulating factor stem-loop destabilizing element involves a single stem-loop that promotes deadenylation. Mol Cell Biol 22:1664-1673.

Quandt K, Frech K, Karas H, Wingender E, Werner T (1995) MatInd and MatInspector: new fast and versatile tools for detection of consensus matches in nucleotide sequence data. Nucleic Acids Res 23:4878-4884.

Rang HP, Bevan S, Dray A (1991) Chemical activation of nociceptive peripheral neurones. Br Med Bull 47:534-548.

Reeh PW, Steen KH (1996) Tissue acidosis in nociception and pain. Prog Brain Res 113:143-151.

Ristimaki A, Garfinkel S, Wessendorf J, Maciag T, Hla T (1994) Induction of cyclooxygenase-2 by interleukin-1 alpha. Evidence for posttranscriptional regulation. J Biol Chem 269:11769-11775.

Rush AM, Brau ME, Elliott AA, Elliott JR (1998) Electrophysiological properties of sodium current subtypes in small cells from adult rat dorsal root ganglia. J Physiol (Lond) 511:771-789.

Steen KH, Reeh PW (1993) Sustained graded pain and hyperalgesia from harmless experimental tissue acidosis in human skin. Neurosci Lett 154:113-116.

Steen KH, Anton F, Reeh PW, Handwerker HO (1990) Sensitization and selective excitation by protons of nociceptive nerve endings in rat skin, in vitro. Pflügers Arch 415:R106.

Steen KH, Reeh PW, Anton F, Handwerker HO (1992) Protons selectively induce lasting excitation and sensitization to mechanical stimulation of nociceptors in rat skin, in vitro. J Neurosci 12:86-95.

Steen KH, Issberner U, Reeh PW (1995) Pain due to experimental acidosis in human skin: evidence for nonadapting nociceptor excitation. Neurosci Lett 199:29-32.

Stroebel M, Goppelt-Struebe M (1994) Signal transduction pathways responsible for serotonin-mediated prostaglandin $\mathrm{G} / \mathrm{H}$ synthase expression in rat mesangial cells. J Biol Chem 269:22952-22957.

Stucky CL, Abrahams LG, Seybold VS (1998) Bradykinin increases the proportion of neonatal rat dorsal root ganglion neurons that respond to capsaicin and protons. Neuroscience 84:1257-1265.

Sutherland SP, Cook SP, McCleskey EW (2000) Chemical mediators of pain due to tissue damage and ischemia. Prog Brain Res 129:21-38.

Sutherland SP, Benson CJ, Adelman JP, McCleskey EW (2001) Acidsensing ion channel 3 matches the acid-gated current in cardiac ischemia-sensing neurons. Proc Natl Acad Sci USA 98:711-716.

Szallasi A, Blumberg PM (1999) Vanilloid (capsaicin) receptors and mechanisms. Pharmacol Rev 51:159-212.

Taiwo YO, Levine JD (1992) Serotonin is a directly-acting hyperalgesic agent in the rat. Neuroscience 48:485-490.

Tominaga M, Caterina MJ, Malmberg AB, Rosen TA, Gilbert H, Skinner K, Raumann BE, Basbaum AI, Julius D (1998) The cloned capsaicin receptor integrates multiple pain-producing stimuli. Neuron 21:531-543.

Voilley N, de Weille J, Mamet J, Lazdunski M (2001) Nonsteroid anti- 
inflammatory drugs inhibit both the activity and the inflammationinduced expression of acid-sensing ion channels in nociceptors. J Neurosci 21:8026-8033.

Waldmann R, Lazdunski M (1998) H(+)-gated cation channels: neuronal acid sensors in the $\mathrm{NaC} / \mathrm{DEG}$ family of ion channels. Curr Opin Neurobiol 8:418-424.

Waldmann R, Champigny G, Voilley N, Lauritzen I, Lazdunski M (1996) The mammalian degenerin MDEG, an amiloride-sensitive cation channel activated by mutations causing neurodegeneration in Caenorhabditis elegans. J Biol Chem 271:10433-10436.

Waldmann R, Champigny G, Bassilana F, Heurteaux C, Lazdunski M (1997a) A proton-gated cation channel involved in acid-sensing. Nature 386:173-177.

Waldmann R, Bassilana F, de Weille J, Champigny G, Heurteaux C, Lazdunski M (1997b) Molecular cloning of a non-inactivating protongated $\mathrm{Na}^{+}$channel specific for sensory neurons. J Biol Chem 272:20975-20978.

Watkins LR, Wiertelak EP, Goehler LE, Smith KP, Martin D, Maier SF
(1994) Characterization of cytokine-induced hyperalgesia. Brain Res 654:15-26.

Waxman SG, Dib-Hajj S, Cummins TR, Black JA (1999a) Sodium channels and pain. Proc Natl Acad Sci USA 96:7635-7639.

Waxman SG, Cummins TR, Dib-Hajj S, Fjell J, Black JA (1999b) Sodium channels, excitability of primary sensory neurons, and the molecular basis of pain. Muscle Nerve 22:1177-1187.

Woolf CJ (1996) Phenotypic modification of primary sensory neurons: the role of nerve growth factor in the production of persistent pain. Philos Trans R Soc Lond B Biol Sci 351:441-448.

Woolf CJ, Costigan M (1999) Transcriptional and posttranslational plasticity and the generation of inflammatory pain. Proc Natl Acad Sci USA 96:7723-7730.

Zur KB, Oh Y, Waxman SG, Black JA (1995) Differential up-regulation of sodium channel alpha- and beta 1-subunit mRNAs in cultured embryonic DRG neurons following exposure to NGF. Brain Res Mol Brain Res 30:97-105. 